\title{
Alteration of serum dehydroepiandrosterone and its sulfated derivative in hypothyroidism
}

\author{
Sumeru Samanta ${ }^{1}$, Ranadip Mukherjee ${ }^{2, *}$, Nityanand Upadhyay ${ }^{3}$ \\ ${ }^{\mathbf{1}}$ Assistant Professor, Dept. of Biochemistry, Bareilly International University, Uttar Pradesh, ${ }^{2}$ Assistant Professor, Dept. of \\ Biochemistry, SRMS Institute of Medical Sciences, Bareilly, Uttar Pradesh, ${ }^{\mathbf{3}}$ Associate Professor, Dept. of Pathology, BIU \\ RCPM, Bareilly, Uttar Pradesh, India
}

*Corresponding Author: Ranadip Mukherjee

Email: ranadip_mukherjee83@yahoo.co.in

Received: $13^{\text {th }}$ July, 2018

Accepted: $18^{\text {th }}$ August, 2018

\begin{abstract}
Introduction: Dysfunction of thyroid gland are among the most common disease of endocrine glands which affect a considerable portion of the population. Thyroid abnormalities are accompanied by changes in various intermediary metabolism which results in body weight alteration, insulin resistance, lipid profile and various biochemical parameters. Changes in dehydroepiandrosterone (DHEA) and its sulfated metabolite (Dehydroepiandrosterone sulfate) have been reported in patients with thyroid hypofunction but the evidence is controversial and not yet established. The present study planned to explore the association between thyroid function with DHEA and DHEAS levels in hypothyroid patients.

Materials and Methods: An observational case control study was conducted in OPD patients of Rajshree Medical College of Rohilkhand region. RMRI, Bareilly.70 newly diagnosed hypothyroid patients were selected and all the biochemical parameters (plasma glucose, thyroid profile, DHEA and DHEAS) were compared with 70 age and sex matched healthy euthyroid controls. Statistical analysis was done using SPSS 22.0. version.

Results: We found that serum DHEA and DHEAS levels were significantly reduced in hypothyroid patients as compared to control $(\mathrm{p}<0.0001)$. Significant negative correlation was observed between DHEA and its sulfated form with TSH and positive association with thyroid hormones (T3, T4, fT3, fT4).

Conclusion: The present study demonstrated that hypothyroidism is associated with significantly low levels of DHEA and DHEAS concentration. Alteration of these sterols in hypothyroidism clearly indicates that thyroid hormone may stimulate the synthesis of these androgen precursors, though more elaborate study with increased sample size may provide more insights.
\end{abstract}

Keywords: Hypothyroidism, Dehydroepiandrosterone, Dehydroepiandrosterone sulfate.

\section{Introduction}

Thyroid dysfunction is among the most common disease of endocrine gland which affects a considerable portion of the population. ${ }^{1}$ Data from various research world wide suggest that, globally 2 billion people are affected by thyroid dysfunction and in India approximately 42 million people suffer from thyroid abnormalities. ${ }^{2}$ Hypothyroidism is a disorder in which the thyroid gland is unable to synthesize and secrete sufficient amount of thyroid hormones to meet the requirement of the peripheral tissue. ${ }^{3}$ Primary hypothyroidism refers to thyroid hypofunction due to disease of thyroid gland itself. This condition manifests for over $99 \%$ of all patients with hypothyroidism. ${ }^{4}$ Overt hypothyroidism describes moderate to severe thyroid dysfunction resulting in increase serum TSH usually above $10 \mathrm{IU} / \mathrm{L}$ in combination with reduce serum concentration of total thyroxine (T4) or free T4. ${ }^{1}$ The incidence of hypothyroidism is estimated to be 4 to 5 per 1000 population per year for females and 0.6 to 0.9 per 1000 population per year for males. ${ }^{5}$ The prevalence of overt hypothyroidism is nearly $1 \%$ to $2 \%$ in women and $0.1 \%$ in men. ${ }^{6}$ The thyroid hormones play key roles in the regulation of bodily functions by stimulate diverse metabolic activities in most tissues, leading to an increase in basal metabolic rate and increase heat production. ${ }^{7}$

Dehydroepiandrosterone (DHEA) and its sulfate ester, dehydroepiandrosterone sulfate (DHEAS), are the most important endogenous circulating hormones synthesized from zona reticularis of adrenal cortex ${ }^{8}$ is one of the most crucial hormone and frequently called "the mother hormone" because it constitute the base for the biochemical actions of important hormones like testosterone, estrogen, progesterone and corticosterone. ${ }^{9}$ It has been suggested that DHEA and DHEAS have some protective effect against cardiovascular diseases, diabetes mellitus, and other immune modulated diseases. ${ }^{10}$ Epidemiological studies have shown a relationship between the progression decrease in circulating DHEAS levels and the increase in cardiovascular morbidity in men. ${ }^{11}$ Interestingly low levels of DHEA have been linked to the development of various diseases including thyroid dysfunction. ${ }^{12}$ As cholesterol is the main precursors for synthesis of DHEA and serum concentration of cholesterol is known to change markedly in patients with thyroid dysfunction; an association may exist between DHEA levels and thyroid dysfunction. ${ }^{13}$ Studies by Ford HC et al suggested that thyroid dysfunction mainly thyrotoxicosis leads to a rise in serum sex hormone 
binding globulin (SHBG) concentration which is accompanied by an increase in testosterone concentration. ${ }^{14}$ On the other hand plasma binding activity of SHBG is decreased in hypothyroidism, which results in decrease testosterone and estradiol concentration. ${ }^{15}$ In addition thyroid hormone binding globulin (TBG) are increased by excess estrogen and decreased by excess androgen. ${ }^{16}$ So there might be complex interaction exist between thyroid axis and production of androgen precursors, i.e. DHEA and DHEAS. But only very few data is available and less is known about the serum concentration of DHEA and DHEAS in patients with thyroid dysfunction. F Bassi et al reported that DHEAS secretion is impaired in women with primary hypothyroidism. ${ }^{17}$ Noriko et al. reported that serum concentrations of DHEA and DHEAS were significantly reduced in hypothyroidism. ${ }^{18}$ Though there are few studies conducted regarding the levels of serum DHEA and DHEAS in thyroid dysfunction, they are conducted on Japanese and European population. But no data is available in Indian population, which prompted us to evaluate DHEA and DHEAS in thyroid dysfunction.

\section{Materials and Methods}

An observational case control study was carried out in the Biochemistry department for approximately 18 months duration from March 2015 to October 2016 in RMRI, Bareilly. Ethical clearance was obtained from Institutional Ethical Committee bearing reference no RMRI. Bly/2014-15/101.

70 newly diagnosed hypothyroid patients were taken as cases and 70 gender and age matched healthy euthyroid subjects were taken as controls for the study. The diagnosis of hypothyroidism depended on the clinical features and biochemical test. The clinical features include weight gain inspite of loss appetite, cold intolerance, dry skin, bradycardia, puffiness of the face and visible or palpable thyroid, while the biochemical tests depended mainly on elevated serum TSH, low serum T3, T4, fT3 and fT4 level. ${ }^{19}$ Written informed consents were taken from all the subjects after explaining the usefulness for the study.

\section{The following patients were excluded from our study:}

1. Subjects with any kind of medication.

2. Prostatic hyperplasia.

3. Know case of diabetes, Tuberculosis.

4. Chronic hypertensive patients and pre-diagnosed HIV patients.

5. Pregnancy and women on OCP.

6. Subclinical hypothyroidism.

\section{Biochemical Analysis}

The procedure was standardized and followed as per the guidelines of The National Committee for clinical laboratory standards (NCCLS). ${ }^{20}$
Modified OSHA (Occupational safety and health act, 1970) guidelines are implemented in all steps of sample collection, processing \& handling of biomedical waste product. ${ }^{21}$

$4 \mathrm{ml}$ of fasting blood specimen was collected for analyzing various parameters. Before collecting venous blood sample using standard venipuncture subjects were asked to have a fasting period of $12 \mathrm{hrs}$. For the standardization blood was drawn in sitting position from antecubital vein. These samples were collected in two different vials, One plain vial for measuring the thyroid profile (T3, T4, fT3, fT4 and TSH), DHEA and DHEAS. One for measuring fasting plasma glucose in sodium fluoride vial. The serum was aspirated after centrifugation at $3000 \mathrm{rpm}$ for 10 minutes. Then serum was divided into aliquots in eppendroff tubes and stored in the freezer $\left(-20{ }^{\circ} \mathrm{C}\right)$ until used. Elisa kits were procured from Avantor for thyroid profile, DRG for DHEA and Calbiotech for DHEAS estimation and tests were performed by using Erba Lisascan II ELISA reader and Erba Chem-7 semi-autoanalyzer.

\section{Statistical Analysis}

The data was processed and appropriate statistical analysis was done by using licensed Microsoft Excel 2007 and SPSS version 22.0. Software ((SPSS Inc. Chicago, IL, USA) to determine the relative association/ correlation of serum DHEA, DHEAS in hypothyroid and control subjects. All data were represented as "mean $\pm S D$ ". Student's ' $t$ ' test was applied to see the statistical significance of variables between hypothyroid group and control group. All the results were considered to be statistically significant if $p$ $\leq 0.05$. Co-efficient of correlation ' $r$ ' was determined between different biochemical indices by using Pearson product moment correlation. For cut off value of DHEA and DHEAS ROC curve analysis was performed.

\section{Results}

Table 1 represents the age and sex distribution of our study population for hypothyroid cases and controls. In our study with respect to gender we found women were more predisposed thyroid dysfunction as supported by the obtained data which suggested $61 \%$ of thyroid dysfunction cases were females among the collected samples in our hospital for 18 months sample collection period. The mean age group of hypothyroid cases was $37.47 \pm 4.97$ years and mean age of controls was $37.18 \pm 5.03$ years. In our study the number of female patients (43/70) was more than that of males (27/70). We also observed that majority of hypothyroid patients in our study was in the age group of 36 to 45 years $(n=42)$.

The serum level of all thyroid parameters of hypothyroid cases and controls were shown in Table 2. It was observed that TSH value was significantly increased in hypothyroid group $(47.77 \pm 23.79 \mu \mathrm{IU} / \mathrm{ml})$ 
with $p$ value $(p<0.0001) . \mathrm{T}_{3}, \mathrm{~T}_{4}, \mathrm{fT}_{3}, \mathrm{fT}_{4}$ values were significantly reduced $(\mathrm{p}<0.0001)$.

Comparison of various biochemical parameters is shown in Table 3. In our study mean fasting plasma glucose in hypothyroid group was $89.22 \pm 11.58 \mathrm{mg} / \mathrm{dl}$, while fasting plasma glucose in control group was $84.16 \pm 10.76 \mathrm{mg} / \mathrm{dl}(\mathrm{p}=0.008)$.

The mean serum DHEA level in hypothyroid group was $4.42 \pm 1.70 \mathrm{ng} / \mathrm{ml}$ as compared with control group it was found $6.04 \pm 2.25 \mathrm{ng} / \mathrm{ml}$. From the results obtained, it was evident that serum DHEA was significantly lower in hypothyroid group in comparison to control group. When compared by Student's ' $t$ ' test the ' $p$ ' value obtained between hypothyroid group and control group was $<0.0001$ which was highly significant. When compared by Pearson's product moment correlation serum DHEA levels in hypothyroid group was significantly negatively correlated with serum TSH with ' $r$ ' value -0.675 [Fig. 1]. Significant positive correlations were observed between serum DHEA with T3 (r=0.20), T4 (r=0.32), fT3 ( $r=0.38)$ and fT4 $(r=0.28)$ levels [Table 4]. On ROC curve analysis the best cut off value of serum DHEA was $5.01 \mathrm{ng} / \mathrm{ml}$ for hypothyroid group from control group with $73 \%$ sensitivity and $80 \%$ specificity with area under curve 0.716 and standard error 0.035 which suggests that serum DHEA can act as a potential differentiator between hypothyroid cases and controls [Fig. 2].

According to our study findings serum DHEAS level in hypothyroid group was $2.57 \pm 1.15 \mu \mathrm{g} / \mathrm{ml}$, while serum DHEAS level in control group was $3.38 \pm 1.15$ $\mu \mathrm{g} / \mathrm{ml}$ [Table 3]. It was evident that mean serum DHEAS was significantly lower in hypothyroid group in comparison to control group. When compared by Student's ' $t$ ' test the ' $p$ ' value obtained between hypothyroid group and control group was $<0.0001$ which was highly significant. When compared by Pearson's product moment correlation serum DHEAS levels in hypothyroid group was found to be significantly negatively correlated with serum TSH (r=$0.671)$ [Fig. 3] and with positively correlated with $\mathrm{T} 3$ $(\mathrm{r}=0.36), \mathrm{T} 4 \quad(\mathrm{r}=0.44)$, fT3 $(\mathrm{r}=0.35)$ and fT4 $(\mathrm{r}=0.48)$ [Table 4]. On ROC curve analysis the best cut off value of serum DHEAS was $3.07 \mu \mathrm{g} / \mathrm{ml}$ for hypothyroid group from control group with $63 \%$ sensitivity and $67 \%$ specificity with area under curve 0.689 [Fig. 4].

Table 1: Age and sex distribution of cases and controls

\begin{tabular}{|l|c|c|}
\hline Parameters & $\begin{array}{c}\text { Controls }(\mathbf{n}=\mathbf{7 0}) \\
(\text { Mean } \pm \text { SD) }\end{array}$ & $\begin{array}{c}\text { Hypothyroid cases }(\mathbf{n}=\mathbf{7 0}) \\
\text { (Mean } \pm \text { SD) }\end{array}$ \\
\hline Age $($ Yrs $)$ & $37.18 \pm 5.03$ & $37.47 \pm 4.97$ \\
\hline Mean age of Males & $37.04 \pm 5.16$ & $37.59 \pm 5.32$ \\
\hline Mean age of Females & $37.13 \pm 5.41$ & $37.43 \pm 4.92$ \\
\hline
\end{tabular}

Table 2: Thyroid function test in hypothyroid cases and controls

\begin{tabular}{|l|c|c|c|}
\hline Parameter & $\begin{array}{c}\text { Controls } \\
(\text { Mean } \pm \text { SD })\end{array}$ & $\begin{array}{c}\text { Hypothyroid cases } \\
(\text { Mean } \pm \text { SD })\end{array}$ & p-value \\
\hline T3 $(\mathrm{ng} / \mathrm{ml})$ & $1.29 \pm 0.30$ & $0.47 \pm 0.17$ & $<0.0001$ \\
\hline T4 $(\mu \mathrm{g} / \mathrm{dl})$ & $7.18 \pm 1.89$ & $2.75 \pm 1.27$ & $<0.0001$ \\
\hline FT3 $3 \mathrm{pg} / \mathrm{ml})$ & $2.85 \pm 1.05$ & $1.01 \pm 0.38$ & $<0.0001$ \\
\hline FT4 $(\mathrm{ng} / \mathrm{dl})$ & $1.35 \pm 0.41$ & $0.61 \pm 0.35$ & $<0.0001$ \\
\hline TSH $(\mu \mathrm{IU} / \mathrm{ml})$ & $2.77 \pm 1.28$ & $44.31 \pm 24.17$ & $<0.0001$ \\
\hline
\end{tabular}

Table 3: Comparison of assed biochemical parameters between hypothyroid cases and controls

\begin{tabular}{|l|c|c|c|}
\hline \multicolumn{1}{|c|}{ Parameters } & $\begin{array}{c}\text { Controls } \\
(\text { Mean } \pm \text { SD) }\end{array}$ & $\begin{array}{c}\text { Hypothyroid cases } \\
(\text { Mean } \pm \text { SD) }\end{array}$ & p- value \\
\hline Fasting plasma glucose $(\mathrm{mg} / \mathrm{dl})$ & $84.16 \pm 10.76$ & $89.22 \pm 11.58$ & 0.008 \\
\hline DHEA $(\mathrm{ng} / \mathrm{ml})$ & $6.04 \pm 2.25$ & $4.42 \pm 1.70$ & $<0.0001$ \\
\hline DHEAS $(\mu \mathrm{g} / \mathrm{ml})$ & $3.38 \pm 1.15$ & $2.57 \pm 1.15$ & $<0.0001$ \\
\hline
\end{tabular}

Table 4: Correlation of Serum DHEA and DHEAS with thyroid hormones in hypothyroid cases

\begin{tabular}{|l|c|c|c|}
\hline Parameter & Variables & Pearson Correlation (r) & 'p' Value \\
\hline \multirow{3}{*}{ Serum } & T3 & 0.20 & 0.04 \\
\cline { 2 - 4 } & T4 & 0.32 & 0.001 \\
\cline { 2 - 4 } & fT3 & 0.38 & 0.000 \\
\cline { 2 - 4 } & fT4 & 0.28 & 0.004 \\
\cline { 2 - 4 } Serum & T3 & 0.36 & 0.001 \\
\cline { 2 - 4 } & T4 & 0.44 & 0.000 \\
\cline { 2 - 4 } & fT3 & 0.35 & 0.003 \\
\hline
\end{tabular}




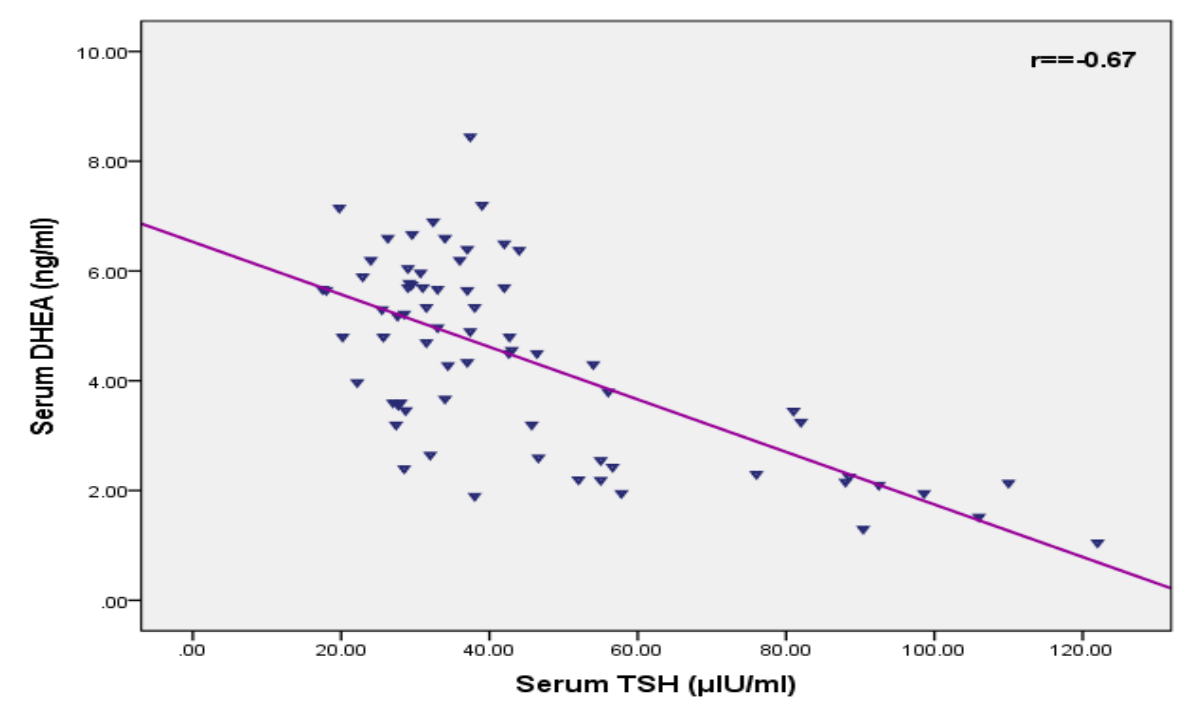

Fig. 1: Diagram showing correlation of serum DHEA in cases with TSH

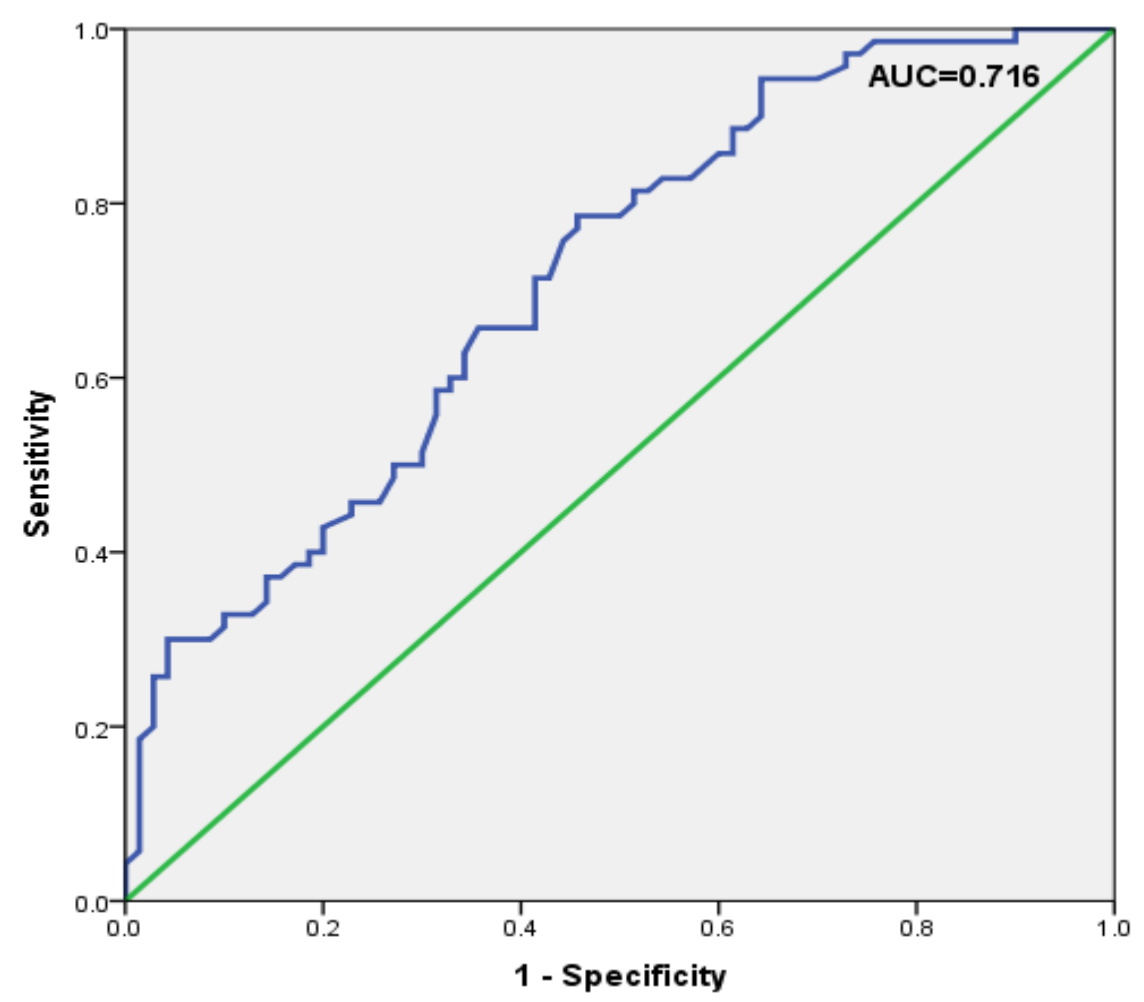

Fig. 2: ROC curve of serum DHEA level in controls \& hypothyroid cases 


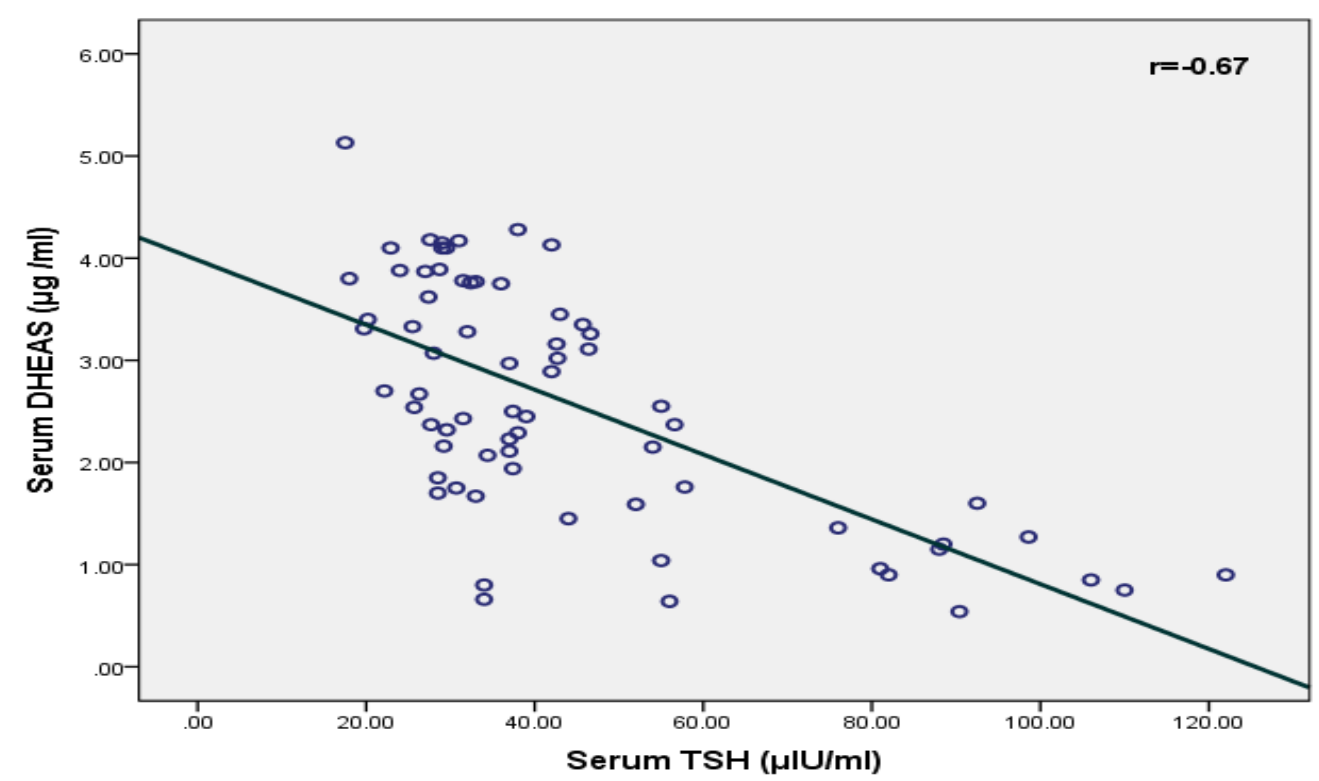

Fig. 3: Diagram showing correlation of serum DHEAS in cases with TSH

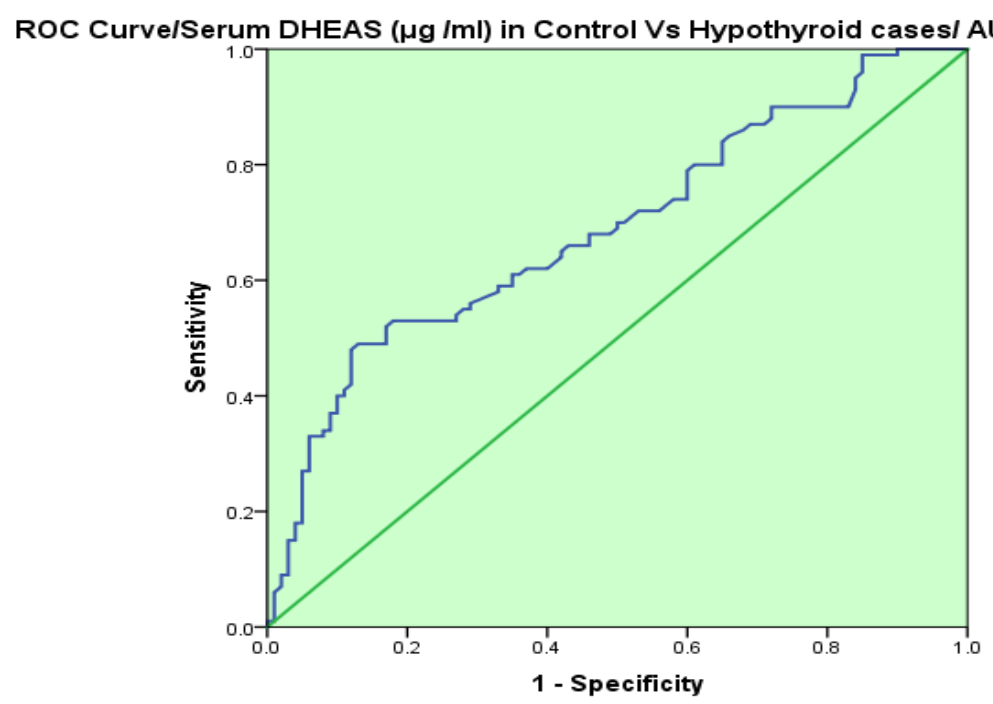

Fig. 4: ROC curve of serum DHEAS level in controls \& hypothyroid cases

\section{Discussion}

Patients with disturbances of thyroid function often manifest changes in intermediary metabolism including alteration of various metabolic parameters, body weight, food uptake, thermogenesis, insulin resistance and lipid profile..$^{22,23}$ Alteration of these biochemical parameters are very much responsible for the pathological changes and various complications in thyroid disorders. The present study set out to look at the possible relationship between thyroid function and some biochemical parameters (FPG, DHEA, DHEAS) in hypothyroid patients.

We found that fasting plasma glucose levels of hypothyroid cases were higher than controls. Mean FPG concentration was found to be significantly increased in hypothyroid cases than controls with 'p' value 0.008. Studies suggest that hypothyroidism is associated with hyperinsulinemia. ${ }^{24}$ In hypothyroid subjects the slowed metabolic state not only slows the rate of glucose absorption from the gastro intestine tract, but it also decrease the glucose utilization because of insulin resistance. ${ }^{24,25}$ In our study, the significant higher FPG in hypothyroid group in comparison to that of control group, pointed to the possibility that hyper insulinemia and insulin resistance may be causing slight increase in the glucose levels.

From this study it was evident that serum DHEA and DHEAS levels were significantly lower in hypothyroid cases in comparison with control group $(\mathrm{p}<0.0001)$. Serum DHEA levels in hypothyroid cases were found to be significantly negatively correlated with serum TSH $(r=-0.675, p=0.000)$ and DHEAS level also significantly negatively correlated with serum TSH 
$(\mathrm{r}=-0.671, \mathrm{p}=0.000)$. On the other hand all the thyroid hormone parameters were significantly positive correlated both with DHEA and DHEAS [Table 4]. On ROC curve analysis the best cut off value of serum DHEA was $5.01 \mathrm{ng} / \mathrm{ml}$ for hypothyroid group from control group with $73 \%$ sensitivity and $80 \%$ specificity. Upon ROC curve analysis the best cut off value of serum DHEAS was $3.07 \mu \mathrm{g} / \mathrm{ml}$ for hypothyroid group from control group with 63\% sensitivity and 67\% specificity. Higher sensitivity and specificity of DHEA indicates that serum DHEA can act as a better potential differentiator between hypothyroid cases and controls than serum DHEAS.

Our study findings was in full agreement with the study conducted by Noriko Tagawa et al. who evaluated DHEA \& DHEAS levels in 24 hypothyroid patients and compared with age and gender matched healthy euthyroid subjects. They reported that DHEA \& its sulfated forms were significantly lower in patients with thyroid dysfunction. ${ }^{18}$ Serum concentration of these steroids correlated significantly with various thyroid hormones but strongest value was observed between fT4 in their study. Serum binding proteins of these sterols i.e. albumin and SHBG levels were also observed and they found that only slight perturbation occurred as a result of thyroid dysfunction. Only a small portion of serum DHEA binds to SHBG, and 90\% of these steroids binds weakly to albumin. ${ }^{26}$ Likewise, $>90 \%$ of serum DHEAS binds weakly to albumin, but DHEAS does not bind SHBG. ${ }^{27}$ So they concluded that the alteration of DHEA and DHEAS was not due to small changes in binding proteins. The present study result was in consonance with studies conducted by $\mathrm{F}$ Bassi et al. who evaluated DHEAS levels in 15 normal premenopausal women and found that DHEAS levels were significantly reduced $(p<0.001)$ in all the subjects. They clearly concluded that DHEAS secretion was impaired in some women with primary hypothyroidism. ${ }^{17}$ The study findings also in accordance with the research findings conducted by $\mathbf{J}$ Foldes et al. who studied serum DHEA and DHEAS levels in female subjects aged between 25 and 45 years. ${ }^{28} \mathrm{~A}$ highly significant decrease of DHEA as well as DHEAS level in patients with hypothyroidism was reported by their study. Our finding was also in agreement with another study conducted by Noriko Tangawa et al. who evaluated DHEA and DHEAS along with other sterols in 31 untreated patients with hypothyroidism..$^{29}$ They clearly stated that serum concentrations of these sterols mainly DHEA and DHEAS were decreased significantly in hypothyroidism. There was no significant difference between male and female values of DHEA and DHEAS. All these sterols were strongly correlated with fT3 and fT4. Our study result was in consonance with studies conducted by K Darvalova et al. who also reported low levels of these sterols in hypothyroid patients. ${ }^{30}$ They also reported negative correlation of these steroids with TSH, along with their positive correlation with both free thyroid hormones.

Recent researches in understanding the physiological roles of DHEA and DHEAS has advanced the study of serum DHEA and DHEAS in various diseases. However, little attention has been given to patients with thyroid dysfunction. In our present study it was clearly observed that DHEA and DHEAS levels were significantly reduced in hypothyroidism. Significant correlation was observed between serum thyroid hormones and DHEA and DHEAS suggesting that thyroid hormone modulate serum concentration of DHEA and DHEAS. Cholesterol acts as a precursors for synthesis of steroid hormones in the adrenal gland and other organs. In the synthesis process, the side chain of cholesterol at C$17 / \mathrm{C}-20$ is cleaved by cholesterol side chain cleavage enzyme (cytochrome $\left.\mathrm{P}-450_{\mathrm{SCC}}\right),{ }^{31}$ producing PREG. This rate determining step controls the biosynthesis of all sterol hormones, including DHEA and DHEAS. In thyroidectomy, a significant decrease in the activity of $\mathrm{P}-450_{\text {SCC }}$ in rat adrenal cortex was observed. ${ }^{32}$ Therefore the significantly reduce levels of DHEA and DHEAS in hypothyroid patients could be explained by the decreased adrenal steroidogenesis induced by low thyroid hormone concentration. As a result of decrease in the activity of P-450 $0_{\mathrm{SCC}}$, blood cholesterol pool is increased and this mechanism possible contribute to hypercholesterolemia in hypothyroid patients in addition to the already illustrated factors.

\section{Conclusion}

Our study clearly revealed that hypothyroidism is associated with significantly low levels of DHEA and DHEAS concentration. Low level of DHEA and its sulfated form in overt hypothyroidism clearly indicates that thyroid hormone may trigger the synthesis of these steroids. Decrease DHEA and DHEAS levels are associated with increased risk of cardiovascular diseases along with increased BMI, shorter life span, reduced bone mineral density, which may also suggest that low levels of these steroid might be responsible for various pathophysiology associated with thyroid dysfunction and more research is required to establish this fact. Our study has some limitations. There are many causes for overt hypothyroidism. First we did not classify the causes into different subgroups according to the causes within study period, which would result in small sample size of subgroups and may not remain statistically relevant. Another limitation of this study was less sample size and the study was conducted in particular region and samples were collected from patients who had arrived in our hospital so like any case control study our study also includes selection bias. So a prospective, multicentric study with larger sample size could obtain wider insights. 


\section{References}

1. Shlomo Melmed, Kenneths S. Polonsky P. Reed Larsen, Henry Kronenberg. Thyroid Physiology and diagnostic evaluation. In: Williams Textbook of Endocrinology.12th edition. Philadelphia. Saunders. Elsevier.2011:327-357.

2. Available from: http://www.ias.ac.in/currsci/oct 252000/n\%20 kochupillai. PDF. [Last accessed on 2011 Apr 2].

3. Roberts CG, Ladenson PW. Hypothyroidism. Lancet. 2004;363:793-803.

4. McDemolt MT, Ridgway EC. Hypothyroidism. In: Cooper Ds, ed. Medical management of thyroid disease. 2nd ed. New York. NY: Informa Health care. 2008;145202.

5. Flynn RW, MacDonald TM, Morris AD, Jung RT, Leese GP. The thyroid epidemiology audit and research study: thyroid dysfunction in general population. J Clin Endocrinol Metab. 2004;89:3879-3884.

6. Canaris GJ, Manowitz NR, Mayor G, Ridgway EC. The Colorado thyroid disease prevalence study. Arch Intern Med. 2000;160:526-534.

7. Lopez M, Luis Varela, Sergio R C, Carmen R, Maris J V, Vidya R V et al. Hypothalamic AMPK and fatty acid metabolism mediate thyroid regulation of energy balance. Nat Med. 2010;16:1001-1008.

8. Parker LN, Odell WD. Control of adrenal androgen secretion. Endocr Rev. 1989;4:392-410.

9. Rita Elkins, M.H. DHEA introduction. In: DHEA. Woodland Publishing.1996;1-10.

10. Baulieu EE, Robel P. Dehydroepiandrosterone and dehydroepiandrosterone sulfate, a neuroactive neurosteroid. J Endocrinol. 1996;50:S221-31.

11. Mitchell LE, Sprecher DL, Borecki B, T Rice, P M Laskarzewski, D C Rao. Evidence of an association between dehydroepiandrosterone sulfate and non fatal premature myocardial infarction in males. Circulation. 1994;89:89-93.

12. Shlomo Melmed, Kenneths S. Polonsky, P. Reed Larsen, Henry Kronenberg. The Adrenal gland. In: Williams Textbook of Endocrinology. 12th edition. Philadelphia. Saunders. Elsevier. 2011:1612.

13. Tada H, Irie Y, Yagoro A, Ohya H, Hayashi S, Fushimi $\mathrm{R}$, et al. Serum concentrations of apolipoproteins in patients with thyroid dysfunction. Thyroidolology. 1994;6:93-97.

14. Ford HC, Cooke RR, Keightley EA, Feek CM. Serum levels of free and bound testosterone in hyperthyroidism. Clin Endocrinol. 1992;36(2):187-192.

15. Gordon GG, Southern AL. Thyroid hormone effect on steroid hormone metabolism. Bull N Y Acad Med. 1977;53:241-259.

16. Philip Felig, Lawrence A Frohman. The Thyroid: Physiology, Thyrotoxicosis, Hypothyroidism, and the Painful Thyroid. In: Endocrinology and metabolism. 4th ed. New York: MacGraw Hill Publication. 2001;261-330.

17. F Bassi, A Pupi, P Giannotti, G Fiorelli, G Forti, A Pinchera. Plasma dehydroepiandrosterone sulphate in hypothyroid premenopausal women. Clin endocr. 1980;13(1):111-113.

18. Noriko Tagawa, Junko Tamanaka, Aya Fujinami, Yoshiharu Kobayashi, Toru Takano, Shuji Fukata et al. Serum dehydroepiandrosterone, dehydroepiandrosterone sulfate and pregnenolone sulfate concentrations in patients with hyperthyroidism and hypothyroidism. Clin Chem. 2000; 46:523-528.

19. Jameson JL, Weetman A. Disorders of thyroid gland. In: Jameson JL, editor. Harrison's Endocrinology. London. McGraw Hill Companies Inc;2008. 62-98.
20. National Committee for Clinical Laboratory Standards. Clinical Laboratory Safety: Approved Guidelines. NCCLS document GP17-A. Wayne, PA: National Committee for Clinical Laboratory, 1996.

21. Occupational Exposure to Hazardous Chemicals in the Laboratory. Occupational Safety and Health Administration (OSHA). Document 29 CFR, Part 1910. Fed Reg. 1991;55:3300-35.

22. Heimberg M, Olubadewo JO, Wilcox HG. Plasma lipoproteins and regulation of hepatic metabolism of fatty acids in altered thyroid states. Endocrine Rev. 1985;6:590-607.

23. Pucci E, Chiovato L, Pinchera A. Thyroid and lipid metabolism. Int J Obesity Rel Metab Dis. 2000;24:S109S112.

24. Chen G, Wu J, Lin Y, Huang B, Yao J, Jiang Q et al. Associations between cardiovascular risk, insulin resistance, $\beta$-cell function and thyroid dysfunction: a cross-sectional study in She ethnic minority group of Fujian Province in China. Eur J Endocrinol. 2010;163:775-82.

25. Singh BM, Goswami B, Mallika V, Association between insulin resistance and hypothyroidism in females attending a tertiary care hospital. Indian Journal of Clinical Biochemistry. 2010;25(2):141-45.

26. Dunn JF, Nisula BC, Rodbard D. Transport of steroid hormones: binding of 21 endogenous steroids to both testosterone- binding globulin and corticosteroid binding globulin in human plasma. J Clin Endocrinol Metab. 1981;53:58-68.

27. Plager JE. The binding of androsterone sulfate, etiocholanolone sulfate and dehydroepiandrosterone sulfate by human plasma protein. J Clin Invest. 1965;44:1234-1239.

28. J Foldes, T Feher, Katalin G Feher, Eva Kollin, L Bodrogi. Dehydroepiandrosterone sulphate (DS), dehydroepiandrosterone (D) and free dehydroepiandrosterone (FD) in plasma of patients with thyroid disease. Horm Metabl Res. 1983;15:623-624.

29. Noriko Tagawa, Toru Takano, Shuji Fukata, Kanji Kuma, Hisato Tada, Yukiko Izumi. Serum concentration of Androstenediol and Androstenediol sulfate in patients with hyperthyroidism and hypothyroidism. Endocr $J$. 2001;48(3):345-354.

30. K Darvalova, P Matucha, M Matejkova-Behanova, R Bílek, L Kriz, H Kazihnitkova, R Hampl.

Immunoprotective Steroids and SHBG in Non-Treated Hypothyroidism and their Relationship to Autoimmune Thyroid Disorders. Physiol Res. 2008;57(Suppl. 1):S119S125.

31. Auchus RJ. Overview of dehydroepiandrosterone biosynthesis. Semin Reprod Med. 2004;22(4):281-288.

32. Benelli C, Michel O, Michel R. Effect of thyroidectomy on pregnenolone and progesterone biosynthesis in rat adrenal cortex. J Steroid Biochem. 1982;16:749-754.

How to cite this article: Sumeru S, Mukherjee R, Upadhyay N. Alteration of serum dehydroepiandrosterone and its sulfated derivative in hypothyroidism. Int $\mathbf{J}$ Clin Biochem Res. 2018;5(4):631-637. 